DOI: $\underline{\text { https://doi.org/10.24867/12FA17Novakovic }}$

\title{
PRIMENA GRIDŠEL KONSTRUKCIJE NA PROJEKTU BOTANIČKE BAŠTE U NOVOM SADU
}

\section{THE APPLICATION OF GRIDSHELL STRUCTURE IN THE PROJECT OF BOTANICAL GARDEN IN NOVI SAD}

\author{
Nela Novaković, Bojan Tepavčević, Fakultet tehničkih nauka, Novi Sad
}

\section{Oblast - DIGITALNE TEHNIKE, DIZAJN I PRODUKCIJA U ARHITEKTURI I URBANIZMU}

Kratak sadržaj - Tema ovog rada, bavi se mogućnostima primene gridšel konstrukcija pri projektovanju botaničke bašte u Novo Sadu, kao i načina generisanja takvih modela digitalnim tehnikama.

Ključne reči: gridšel, botanička bašta

\begin{abstract}
The topic of this thesis deals with the possibilities of application of gridshell structure in the project of Botanical Garden in Novi Sad, as well as generating that kind of structure using digital techniques.
\end{abstract}

Keywords: gridshell, botanical garden

\section{UVOD}

Povezanost ljudi sa biljnim svetom i čovekova potreba za uzgajanjem i istraživanjem različitih biljnih vrsta datira od davnina. Prostori na kojima se uzgajaju biljke vremenom su se razvijali uporedo sa razvojem mnogih nauka kao što su hortikultura, botanika i ekologija. Jedan od vrsta takvih prostora je i botanička bašta, koja predstavlja spoj arhitekture i uzgajanja biljaka i predmet je ovog rada.

$\mathrm{U}$ isto vreme arhitektura našeg doba prolazi kroz revoluciju označenu značajnim naporima koji se čine na polju digitalizacije, novih tehnika građenja i energetske efikasnosti. Materijali, postupci u konstruisanju, tehnologija proizvodnje i pravila koja su vekovima vazila gube svoj značaj i zamenjuju se novim ili se proširuju. Teži se sve više za tim da se smanji količina potrebnog materijala i uštedi na radnoj snazi, kao i u celokupnim troškovima i da se pri tome udovolji zahtevima koji se postavljaju arhitekturi.

Predmet master rada jeste idejno rešenje projekta botaničke bašte u Novom Sadu primenom gridšel konstrukcije, koje ima za cilj integraciju organizacije prostora sa konstuktivnim metodama, upotrebom digitalnog dizajna i simulacija.

\section{ANALIZA TIPOLOGIJE}

Botanička bašta je naučno-istraživačka, nastavna i kulturno-prosvetna ustanova u kojoj se nalaze kolekcije živih biljaka koje reprezentuju raznovrsnost i bogatstvo

\section{NAPOMENA:}

Ovaj rad proistekao je iz master rada čiji mentor je bio dr Bojan Tepavčević. biljnog sveta. Ova ustanova, kao svoju glavnu namenu ima sakupljanje, uzgoj, očuvanje i izlaganje širokog spektra biljaka obeleženih njihovim botaničkim imenima. U svojoj biljnoj kolekciji može sadržati specijalne vrste biljaka kao što su kaktusi, biljke iz određenih delova sveta itd., s toga često sadrži staklenike i hladnjače sa posebnim kolekcijama poput tropskih biljaka, alpskih biljaka ili drugih egzotičnih biljaka. Uređuje se po fitogeografskom, sistematskom i ekološkom principu. Usluge posetilaca $\mathrm{u}$ botaničkoj bašti mogu da uključuju ture, obrazovne izložbe, umetničke izložbe, prostorije za knjige, pozorišne i muzičke predstave na otvorenom i drugu zabavu.

Studijom slučaja nekih primera slične tipologije (Botanička bašta Jevremovac, Eden Project, Gardens by the Bay, Nacionalni ekološki institut u Južnoj Koreji) došlo se do zaključka da ova tipologija polako menja način percepcije, organizovanja prostora i svoju ulogu $\mathrm{u}$ društvu. Samim tim, može se zaključiti da botaničke bašte mogu igrati glavnu ulogu u ponovnom povezivanju posetilaca i drugih učesnika sa biodiverzitetom kroz razne programe i istraživanja. Da bi postali relevantni u našem sadašnjem društvu, botanički vrtovi bi trebalo da evoluiraju od tradicionalnih modela istraživanja i hortikultura, kao i percepcije ovakvih institucija kao socijalno elitnih. Ovaj razvoj moguć je usvajanjem raznovrsnih programa kojim bi se proširio sadržaj i kroz pristupačnost i povezanost sa društvenom zajednicom. Ključne kategorije programa u botaničkim vrtovima jesu dodatni sadržaji kao što su javna rekreacija, hortikultura, istraživanje bilja i obrazovanje. Na ovaj način program ovakvih kompleksa bi bio atraktivniji i adekvatniji današnjem društvu.

Istovremeno, nove tehnike građena i novi materijali mogu znatno doprineti ekonomičnosti i energetskoj efikasnosti objekta, ali i u varijacijama arhitektonskih formi koje razvojem ove tipologije sve više poprimaju organski, nepravilan oblik.

\section{ANALIZA KONSTRUKCIJE}

Razvoj prostornih konstrukcija, zasniva se na dve osnovne ideje:

- veza između oblika i moći nošenja, koja je presudna za izbor pogodnog materijala i njegovu količinu, kao i udeo troškova za materijal u ukupnim troškovima

- veza između troškova i tehnologije, koja se ispoljava u radu potrebnom da se utroši za izvedbu, u sredstvima za rad i u troškovima koji iz toga slede.

U prostorne konstrukcije spadaju ljuske, šatorske konstrukcije, pneumatske konstrukcije i druge. Jedan od 
tipova prostornih konstrukcija jesu i gridšel konstrukcije, koje su tema ovog rada.

Evolucia gridšel konstrukcija ima paralelan razvoj sa razvojem tehnologije. Sem estetike, ova konstrukcija pravi blisku vezu između arhitekture, građevinarstva/ statike i zanatlija/digitalne fabrikacije, preklapanjem projektovanja oblika i konstrukcije objekta i mogućnosti za njegovo izvođenje. Savremena gridšel konstrukcija predstavlja razvoj tehnologije, digitalnih metoda „nalaženja forme" i tehnika digitalne fabrikacije $u$ arhitekturi $i$ građevinarstvu.

Prema definiciji, gridšel (od engleske reči gridshell) konstrukcija je prostorna konstrukcija sačinjena od štapova u dva pravca koji su međusobno upravni. Štapovi formiraju planarnu mrežu sa pravougaonom ili romboidnom podelom željene proizvoljne forme i podjednakim rastojanjem između tački spajanja, odnosno preklapanja.

Poređenjem primera gridšela (Gridšel u Manhajmu, Gridšel konstrukcija krova Britanskog muzeja, Weald \& Downland gridšel, Savill Garden gridšel) u studiji slučaja može se dobiti dijagram odnosa težine i pokrivene površine. Kao najveća vrednost težine i pokrivene površine uzeta je težina i površina gridšelja britanskog muzeja i u odnosu na te vrednosti dato je poređenje sa ostalim gridšel konstrukcijama.

Ovaj dijagram pokazuje da su drvene gridšel konstrukcije vrlo efikasan način za premošćavanje velikih raspona i u poređenju sa čeličnim rešetkama. Samim tim, iz dijagrama možemo videti da težina i pokrivena površina Savill Garden gridšela čini oko $40 \%$ od mase i površine Britanskog muzeja. Isto tako, gridšel u Manhajmu teži samo $20 \%$ ukupna težine gridšela Britanskog muzeja, dok pokriva $60 \%$ površine gridšela Britanskog muzeja.

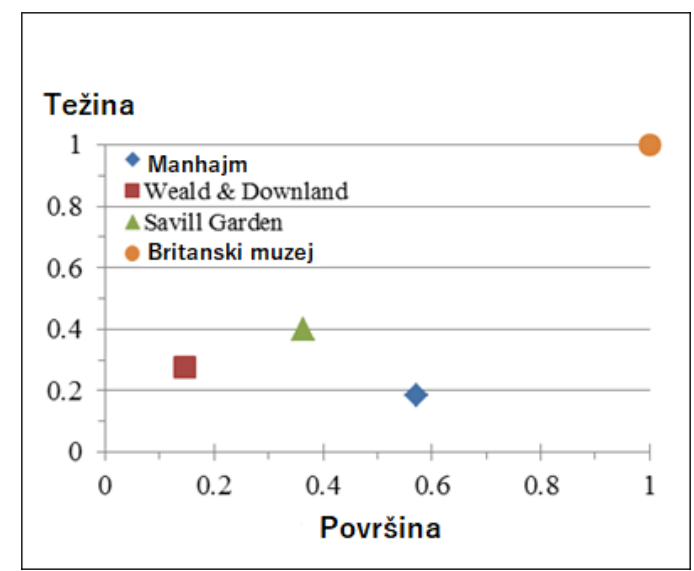

Slika 1. Dijagram odnosa težine i pokrivene površine analiziranih gridšel konstrukcija [2]

Osim činjenice da je ovaj tip konstrukcije samonosiv i da ima znatne prednosti u pogledu ekonomičnosti i smanjena težine konstrukcije, znatne prednosti ovakvog tipa gradnje su i u širokim mogućnostima njegove primene.

Takođe, organski oblici i nepravilne jedinstvene forme koje se mogu dobiti upotrebom gridšela daju autentičnost arhitektonskom izrazu objekata kod kojih je primenjen ovaj tip konstruktivnog sistema.

\section{PROJEKAT BOTANIČKE BAŠTE U NOVOM SADU}

\subsection{Lokacija}

Kao najadekvatnija lokacija za projekat Botaničke bašte odabran je rukavac Dunava u južnom delu grada, na levoj obali Dunava, koji se zove Kamenička ada. Priobalje i klimatske karakteristike područja i sve veća usmerenost stanovništva ka reci, realna su pretpostavka da Dunav, kao prirodni potencijal trenutno, i u perspektivi, može da bude prostor namenjen turizmu, sportu i rekreaciji stanovništva grada i šire.

Prilikom odabira lokacije uzete su u obzir različite analize gradskog područja u odnosu na planiranu parcelu Botaničke bašte (istorijska analiza, ekološka analiza, analiza vizura $\mathrm{i}$ analiza povezanosti).

U skladu sa urbanističkim planom za Kameničku adu, kao adekvatna lokacija odabran je deo parka, odnosno ostrvo u sklopu parka, odvojeno kanalom i smešteno na zapadnom delu ade. Inkorporiran unutar parka, kompleks botaničke bašte svojim nepravilnim oblicima ne narušava izgled sredine, već postaje njegov sasatavni deo.

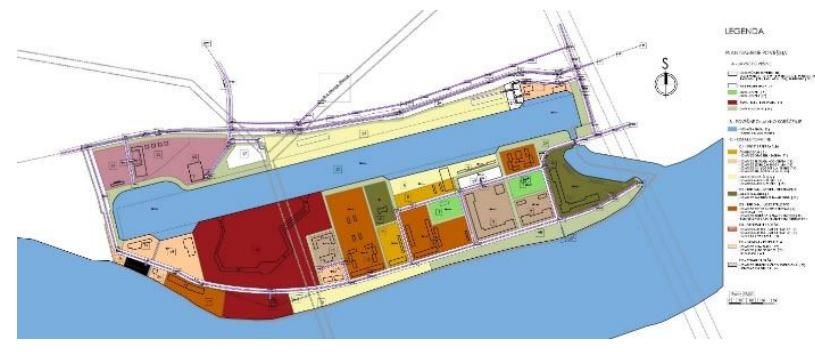

Slika 2. Plan detaljne regulacije Kameničke ade [2]

\subsection{Koncept}

Koncept objekata Botaničke bašte proizilazi iz same lokacije i prirodnog okruženja. Polazna karakteristika u formiranju oblika jeste fluidnost prostora i neprekinuto kretanje unutar kompleksa koje je postignuto organskim formama, kao i prožimanje arhitekture sa spoljašnjim prostorom bašte. Inspiracija za oblikovanje su organske forme nastale usled povlačenja vode na peskovitom terenu (slika 37.). Na taj način nastojano je da se očuva "duh mesta", odnosno da se amorfnim organskim formama sačuva percepcija pejzaža sadašnjeg močvarnog područja na kom je planiran kompleks. Pored toga, objekti su planirani uzimajući u obzir i okolne sadržaje i generalni urbanistički plan ovog dela grada.

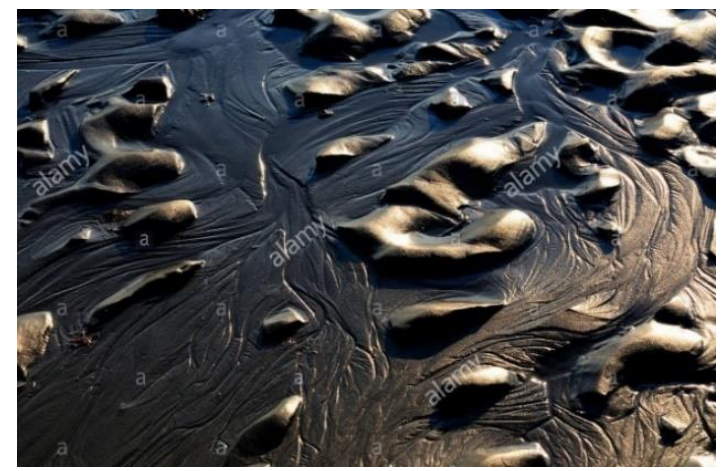

Slika 3. Forme nastale usled povlačenja vode [3] 


\subsection{Funkcionalna organizacija objekta}

Projekat botaničke bašte podeljen je u osnovi na dve celine, a svaka od ove dve celine ima dodatno je izdeljna $\mathrm{u}$ odnosu na njenu namenu. Podela je postignuta otvorenim petprostorom sa nadstrešnicom iz koga se pristupa objektima.

Veći objekat, sa pretežno komercialnom namenom, u svom južnom delu sadrži pretprostor sa garderobom, prostorije za presvlačenje zaposlenih, sanitarni čvor prostor zatvorene bašte $\mathrm{u}$ kome se mogu nalaziti manji staklenici. Severni deo većeg objekta je zamišljen kao prostor u kom se nalazi administracija, kafe i suvenirnica.

U manji objekat, namenjen obrazovanju smeštene su biblioteka sa arhivom i toaletom sa jedne strane i učionice, laboratorije, kancelarije za profesore, amfiteatar i kopirnica sa druge strane objekta.

Prilikom organizacije prostora nastojano je da se prostor prilagodi budućim korisnicima i da odgovori zahtevima savremenih objekata ove tipologije.

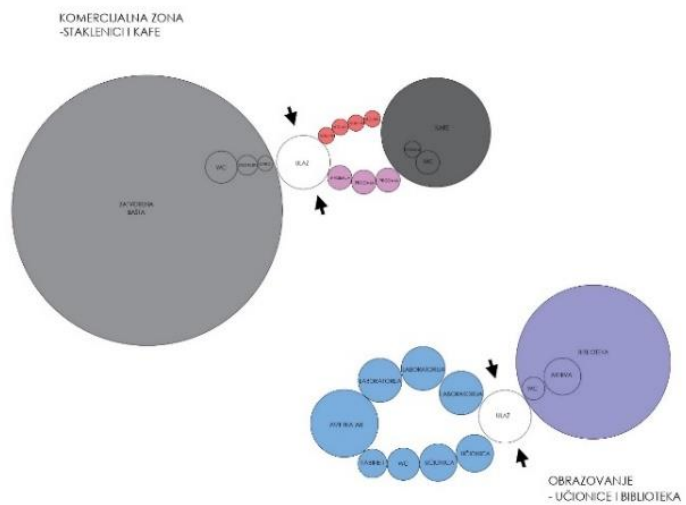

Slika 4. Dijagram namene

\subsection{Konstrukcija}

Osnova objekata formirana je u skladu sa veličinama prostorija i prostornom organizaciom funkcionalne šeme objekata. Unutrašni prostori formirani su shodno konstrukciji. Prilikom oblikovanja objekata i raspoređivanja prostorija vodilo se računa o odnosu raspona u osnovi i spratne visine. Formiranjem atrijumskih prostora nastojano je da se smanji spratna visina prostorija koje zahtevaju nižu spratnost i ujedno ostvari prožetost unutrašnjeg i spoljnog prostora.

Oblik konstrukcije dobijen je digitalnim alatima u Grasshopper i Rhinoceros softverima i upotrebom algoritama za „nalaženja forme” $\mathrm{Na}$ taj način dobijena je optimalna forma koja odgovara početnom konceptu stvaranja organske arhitektonske forme.

Forma je dobijena tako sto je prvo definisana površina koju je potrebno premostiti, odnosno natkriti. Ova površina izdeljena je kvadratnom podelom, a kao rezultat podele dobijene su tačke i linije koje definišu mrežu. Na izdeljenu površinu (po principu sistema čestica i opruga), nakon toga, primenjeno je gravitaciono opterećenje. Tačke predstavljaju mesta delovanja sila, a linije dužinu elastičnih opruga između njih. Kao tačke oslonca definisane su tačke obodnih linija željene forme. Ova tri krajnja parametra definišu izgled gridšel konstrukcije.

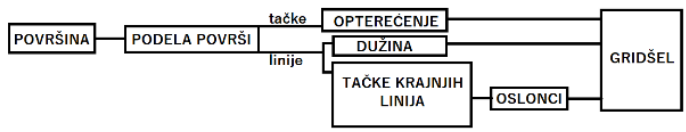

Slika 5. Šematski prikaz algoritma

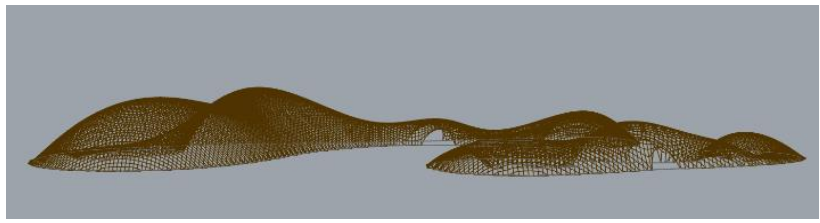

Slika 6. $3 d$ model konstrukcije

\subsection{Pejzažno uređenje}

Stvaranje kontinualnog prostora sa neprekinutim putanjama kretanja, princip je koji je zadržan i u enterijeru i u eksterijeru objekta i koji doprinosi jedinstvenosti i uniformnosti celog projekta. Međutim, kod formiranja eksterijera nije korišten geometrijski početni koncept, već apstraktna pojava vektora kretanja i linija elektromagnetnog polja između naelektrisanih tačaka. U slučaju projekta botaničke bašte tačke predstavljaju pozicije ulaza u objekte prema kojima posetioci gravitiraju, kao i pešačke pristupe parceli kompleksa, a linije koje ih povezuju služe za generisanje pravaca kretanja i usmeravanje posetioca ka objektima. Ovim je postignuta interakcija okoline sa samim objektima, a kretanje kao osnovni generator prostora postalo integralni deo celog projekta povezujući sve prostorne celine. Pomoću alata u Grasshopper-u koji koristi znanja iz fizike i elektrostatike definiše se elektromagnetno polje koje kao ulazne parametre koristi granice polja i tačke kojima se dodeljuje vrednost naelektrisanja.

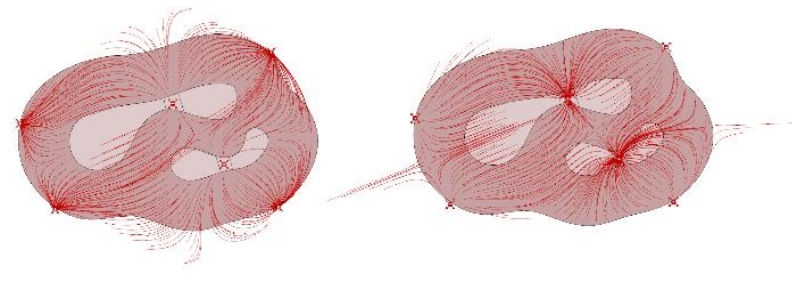

Slika 7. Varijacije linija polja u slučaju jednakog naelektrisanja tačaka na parceli $i$ izvan nje

\subsection{Materijalizacija}

Projektom je predviđeno da gridšel konstrukcija bude dvoslojna, izrađena od drveta, sa dimenzijama poprečnog preseka letvi $8 \times 5 \mathrm{~cm}$.

Od svih materijala drvo najbolje udovoljava zahtevima koji se od materijala traže kada se koriste kao prostorne konstrukcije: mala spostvena težina, zatezna i pritisna čvrstoća baš potrebnom reda veličine, dobra toplotnoizolaciona svojstva, laka obradivost uz pogodnost za mehanizovanu izradu, mogućnost primene najjednostavnijih konstruktivnih spojeva.

Upotreba dvoslojnog sistema, sa četiri niza nosača raspoređenih u dva pravca (slika 2.1), omogućuje postizanje većih zakrivljenosti, a samim tim daje veću slobodu arhitektonskih izraza. Da bi se obezbedila unutrašnja čvrstoća na smicanje i krutost, konstrukcija mora biti dodatno učvršćena dijagonalnim vezama. 
Upotreba dvoslojnog sistema, sa četiri niza nosača raspoređenih u dva pravca (slika 2.1), omogućuje postizanje većih zakrivljenosti, a samim tim daje veću slobodu arhitektonskih izraza. Da bi se obezbedila unutrašnja čvrstoća na smicanje i krutost, konstrukcija mora biti dodatno učvršćena dijagonalnim vezama.

$\mathrm{Na}$ čvorovima koriste čelične ploče između slojeva sa 4 vijka koji povezuju ploče bez probijanja letvi.

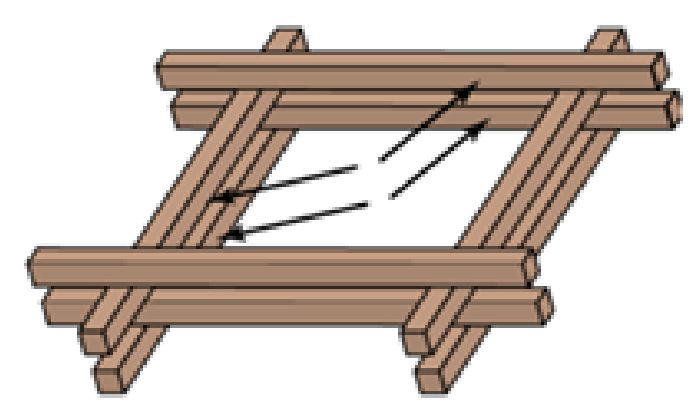

Slika 8. Dodatni element koji umanjuje sejstvo horizontalnih sila [4]

Konstrukcija je obložena ETFE folijom. ETFE (etilentetrafluoroetilenski kopolimer) je derivat plastike koji se često koristi kao građevinski materijal u obliku ETFE membrana. Materijal se odlikuje velikom propusnošću svetlosti i UV zraka, otpornošću na temperaturu i vrlo malom težinom. ETFE folija je otporna na požar i ima tačku topljenja od $270^{\circ} \mathrm{C}$.

Ovo, zajedno sa kvalitetom samočišćenja materijala, osigurava da se ETFE membrane mogu primeniti na različitim vrstama objekata. Funkciju samočišćenja pruža efekat lotosa: posebna površinska struktura osigurava da su vetar i kiša dovoljni za uklanjanje nečistoće sa površine ETFE. Pored toga, membrana se u potpunosti može reciklirati i dostupna je u više boja. Obzirom na malu težinu drvene lamelirane konstrukcije Botaničke bašte, oblaganje fasade ovim materijalom ima prednosti iz aspekata energetske efikasnosti, ekonomičnosti i održavanja objekata.

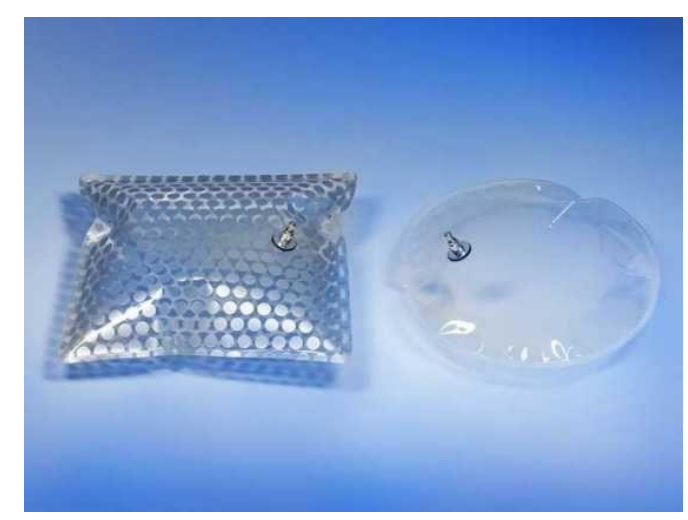

Slika 9. Uzorci ETFE membrane [5]

Unutrašnji pregradni zidovi nepravilnih oblika su debljine $25 \mathrm{~cm}$ od opeke. Izuzetak su zidovi u toaletima koji su ravni i imaju debljinu $10 \mathrm{~cm}$. Određene podele prostora su izvršene i polutransparentnim staklenim panelima (DORMA HSW).

\section{ZAKLJUČAK}

Arhitektura u službi organizovanja i dizajniranja prostora ima za obavezu da prati sve potrebe društva koje se nameću i menjaju tokom vremena. Svaki projektantski problem počinje sa težnjom ka uklapanju forme i njenog konteksta. Pored toga, konstrukcija je glavni faktor koji definiše oblik arhitektonskog dizajna. Povezivanje funkcije, forme i konstrukcije, materijalizacije i njihova neraskidiva veza bi trebalo da postanu suštinski odnosi koje treba analizirati u svakom segmentu projektovanja.

U okviru ovog master rada istraženi su različiti principi i načini primene digitalnog dizajna u arhitekturi, kao i različiti pristupi metodama "nalaženja forme", kako bi se odredio optimalan oblik gridšel konstrukcije. Za projekat Botaničke bašte u Novom Sadu analizirani su digitalni alati kojima se mogu dobiti različite forme samonosive strukture gridšela. Uvođenje prirodnih faktora i njihov uticaj na objekat, kao i obrnuti uticaj i interakcija objekta sa svojim okruženjem predstavljaju jedan od polaznih koncepta i uslova pri generisanju forme u ovom projektu.

$\mathrm{Za}$ razliku od tradicionalnog pristupa ispitivanja forme gridšel konstrukcija, novi pristup upotrebom softvera znatno ubrzava proces i pruža različite mogućnosti za optimizaciju dobijene forme. Ujedno, digitalni dizajnom se povezuje više činilaca koji se analiziraju istovremeno (forma, funkcija, performanse), a ne kao pojedinačni entiteti. Ovim se postiže ne samo energetska i ekonomska efikasnost objekata, već bi se i omogućilo kreiranje novih, kompleksnih formi kao odgovor na lokaciju, prirodni kontekst i potrebe ljudi.

\section{LITERATURA}

[1] https://www.academia.edu/8615523/Timber_Gridshells_Design_methods_and_their_application_to_a_te mporary_pavilion (pristupljeno u oktobru 2020.)

[2] http://www.nsurbanizam.rs/pdr (pristupljeno u oktobru 2020.)

[3] https://1450v.alamy.com/450v/2bmd5k7/white-shell-onsand-2bmd5k7.jpg (pristupljeno u oktobru 2020.)

[4] https://www.academia.edu/8615523/Timber_Gridshells_Design_methods_and_their_application_to_a_te mporary_pavilion (pristupljeno u oktobru 2020.)

[5] https://i.pinimg.com/564x/3b/5d/20/3b5d208e965ed4514b7863db18044edd.jpg (pristupljeno u oktobru 2020.)

\section{Kratka biografija:}

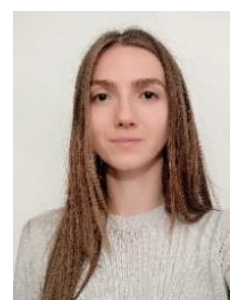

Nela Novaković rođena je u Zenici 1993. god. Master rad na Fakultetu tehničkih nauka iz oblasti Digitalne tehnike, dizajn i produkcija u arhitekturi i urbanizmuPrimena gridšel konstrukcije na projektu botaničke bašte u Novom Sadu odbranila je 2020.god.

kontakt: nelanovakovic7@gmail.com

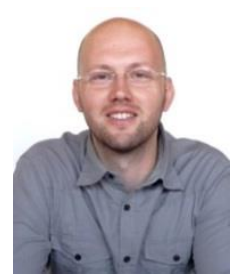

Bojan Tepavčević rođen je u Novom Sadu 1979. Doktorirao je na Fakultetu tehničkih nauka 2010. god., a od 2016. je zvanju vanredni profesor. Oblast interesovanja su digitalni dizajn. 